\title{
Postmenopausal symptoms among Egyptian geripausal women
}

H.S. Sweed, ${ }^{\prime}$ A.E. Elawam, ${ }^{7}$ A.M. Nabeel' and A.K. Mortagy ${ }^{7}$

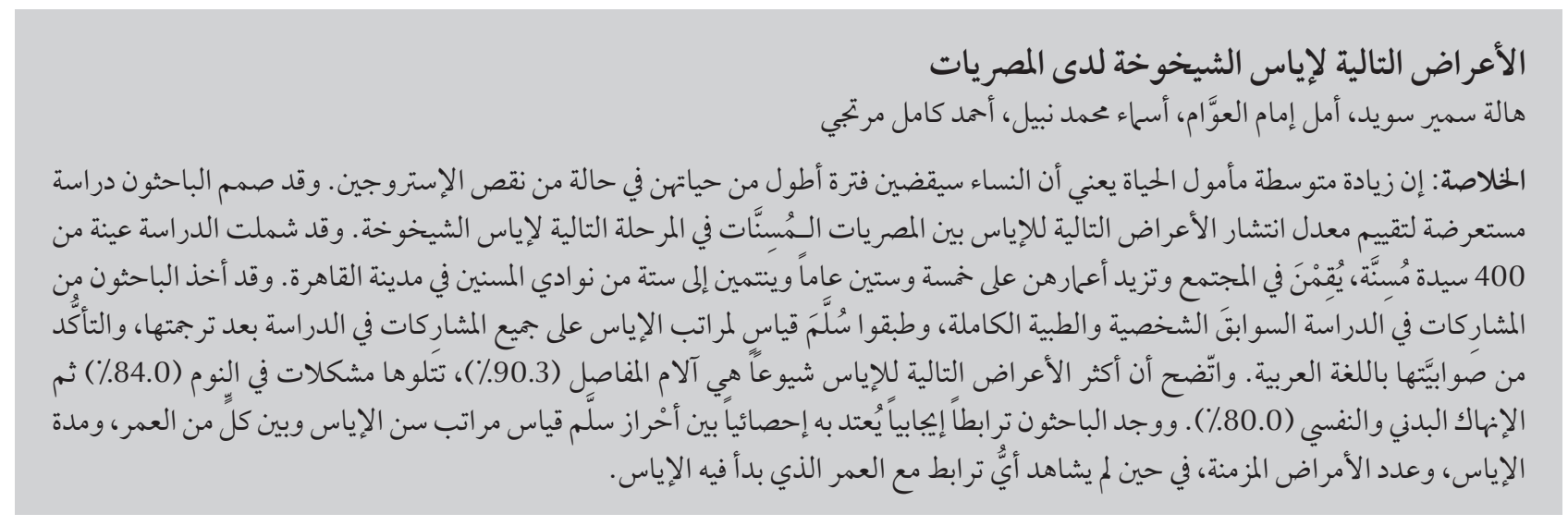

ABSTRACT Increases in life expectancies mean that women are spending longer periods of their life in a hypooestrogenic state. A cross-sectional study was designed to assess the prevalence of postmenopausal symptoms among elderly Egyptian women in the geripausal phase. A sample of 400 community-dwelling elderly women aged $>65$ years were recruited from 6 geriatric social clubs in Cairo. A full personal and medical history was taken from all participants. The menopause rating scale was applied to all participants after translation and linguistic validation in the Arabic language. The most prevalent postmenopausal symptoms were joint pain (90.3\%), followed by sleep problems (84.0\%) and physical and mental exhaustion (80.0\%). A statistically significant positive correlation was found between total menopause rating scale score and age, duration of menopause and number of chronic diseases but not with age of menopause.

\section{Symptômes ménopausiques chez des femmes égyptiennes du troisième et quatrième âge}

RÉSUMÉ L'augmentation de la durée de vie signifie que les femmes passent une proportion plus importante de leur vie dans un état hypo-oestrogénique. Une étude transversale a été élaborée pour évaluer la prévalence des symptômes ménopausiques chez des femmes égyptiennes du troisième et quatrième âge. Un échantillon de 400 femmes âgées de plus de 65 ans et vivant dans la communauté a été recruté dans six clubs pour personnes âgées au Caire. Les données personnelles et les antécédents médicaux complets de toutes les participantes ont été notés. L'échelle Menopause Rating Scale - MRS [échelle d'évaluation de la ménopause] a été utilisée pour toutes les participantes après sa traduction et sa validation en langue arabe. Les symptômes ménopausiques les plus fréquents étaient les douleurs articulaires (90,3\%), suivis par les troubles du sommeil $(84,0 \%)$ et l'épuisement physique et mental $(80,0 \%)$. Une corrélation positive statistiquement significative a été retrouvée entre le score total à l'échelle MRS et l'âge, la durée de la ménopause et le nombre de pathologies chroniques. En revanche, aucune corrélation n'a été observée avec l'âge de survenue de la ménopause. 


\section{Introduction}

The increasing proportion of the population who are not only elderly but the "oldest old" is a concern for policy-makers, especially concerning the health of women, who account for approximately $60 \%$ of all those age $65+$ years and $67 \%$ of those ages $85+$ years $[1,2]$. Despite increasing life expectancies there has been no concomitant change in the average age of menopause (approximately 50-51 years) which means that women are spending longer periods of their life (now up to one-third of the life cycle) in a hypo-oestrogenic state.

It is now clear that the term "postmenopausal" is insufficient to describe the years after menopause [3]. The term "geripause" has been suggested to describe consistent changes in the body due to both oestrogen loss and the impact of ageing and to provide a focus for the management of late menopause [4]. It has been used to characterize a phase of reproductive ageing that begins postmenopause, presenting a new set of endocrinological, metabolic and physiological manifestations with an increase in age-related changes. It has been divided into 2 phases: early geripause ( $65-85$ years age) and late geripause (above 85 years).

The menopause rating scale (MRS) is a well accepted instrument for measuring the severity of menopausal symptoms. It was developed in response to the lack of standardized scales to measure the severity of ageing symptoms and their impact on health-related quality of life. The ease of completion and high repeatability of the test results emphasize its practical applicability [5]. The MRS is recommended for use in clinical practice as being a reliable scale for the measurement and long-term surveillance of menopausal complaint dynamics [5]. This study aimed to develop an Arabic version of the MRS questionnaire and use it to assess postmenopausal symptoms among Egyptian women in the early geripausal phase.

\section{Methods}

\section{Study setting and sample}

A cross-sectional study was conducted in Cairo, Egypt over the period August 2008 to January 2009. The study was carried out in 6 social clubs for elderly people which were randomly selected from a list of geriatric clubs in the city that is reviewed and updated by the Ministry of Social Affairs. The list was provided by the social worker of the Department of Geriatrics and Gerontology of Ain Shams University hospital. The study was reviewed and approved by the research review board of the Department of Geriatrics and Gerontology, Faculty of Medicine, Ain Shams University.

Elderly females dwelling in the community who attended these clubs were approached. Women were excluded if they were taking, or had ever taken, hormone replacement therapy before or after menopause or if they were taking anxiolytics or antidepressants. Explanation of the study aims and procedures was given to all subjects and informed consent for participation was taken from each woman. Those who refused to participate were excluded from the study. A total of 457 elderly females met the study criteria; 30 refused to participate while 27 did not complete the questionnaire. Therefore 400 elderly females aged $65+$ years completed the study.

\section{Data collection}

All participants were interviewed faceto-face by trained health personnel to obtain their demographic details, age of menopause, any history of chronic diseases (self-reported), surgery or medication use and to complete the MRS.

The scale consists of 11 symptoms in 3 domains: somato-vegetative domain (hot flushes, heart discomfort, sleep problems, joint and muscular discomfort); psychological domain (depressed mood, irritability, anxiety, physical and mental exhaustion); urogenital domain (sexual problems, bladder problems and vaginal dryness). Each symptom is scored from none (0) to very severe (4), giving a score range from $0-44$ [6]. Summation scores for severity were classified as: none $/$ little $=0-4$, mild $=5-8$, moderate $=9-16$, severe $/$ very severe $=17+[6]$.

A chronic physical illness summary score [7] was calculated. This score was the sum of 10 common chronic physical conditions: coronary heart disease, hypertension, diabetes, stroke, arthritis, asthma, osteoporosis, thyroid disease, Parkinson disease and cancer. Diagnosis depended on previous physician diagnosis, or available medical records. The scale score range was $0-10$.

\section{Linguistic validation of the Arabic MRS}

The MRS scale was originally developed in German language and then translated into a number of other languages [8]. Translation to Arabic and confirmation of the linguistic validity and reliability of the Arabic version was made for the current study. The translation of the MRS was done according to international methodological recommendations for the linguistic and cultural adaptation of questionnaires [9] using the English version as the source. Six steps of the translation process were followed: forward translation by 2 translators, meeting with the coordinator of the translation, a check by a bilingual expert to evaluate the scientific correctness of the wording, a backwards translation, meeting among the translators with the coordinator, and finally a pretest with a chosen sample. The translated questionnaire was tested on 80 volunteers who were allowed to comment on their understanding on each question. A few statements were changed in the Arabic translation to reflect the same correct meaning in the English version. The stability of the Arabic MRS questionnaire was examined by the test-retest 
method and the Pearson correlation coefficient between the 2 measures, done on the same group of 60 participants 1 week apart, revealed 90\% test-retest agreement.

\section{Statistical methods}

The collected data were coded, tabulated, and statistically analysed using SPSS programme, version 17. Qualitative data was presented in form of frequency tables (number and percentage). Quantitative data was presented in form of mean, standard deviation (SD) and range. Pearson correlation coefficient was performed to test correlation between 2 quantitative variables, while one-way analysis of variance (ANOVA) was used to test for comparison between multiple groups with quantitative continuous variables. Independent sample $t$-test was also used to compare 2 groups with quantitative continuous variables.

\section{Results}

\section{Background characteristics}

Table 1 shows the background characteristics of the women. The study sample included 400 postmenopausal women with a mean age of 68.7 (SD 4.6) years (range 65-86 years), mean recalled age of menopause 49.2 (SD 1.6) years (range 41-56 years) and menopause duration of 19.5 (SD 4.5) years (range 11-36 years). The distribution by age group was as follows: $349(87.3 \%)$ 65-75 years, 43 (10.8\%) 75-85 years and $8(2.0 \%)>85$ years. All of them had been through natural menopause and $3.8 \%(n=15)$ had had a hysterectomy. Marital status was as follows: $34.5 \%$ married, $64.5 \%$ widowed and 1.0\% divorced. The clinical history showed that $70.3 \%$ were hypertensive, $45.3 \%$ were diabetic, $31.8 \%$ had coronary heart disease, $5.0 \%$ were asthmatic, $6.8 \%$ had osteoporosis, $0.8 \%$ had previous stroke, $1.0 \%$ were previously diagnosed with cancer and $1.0 \%$ had thyroid disease.
Presence of diseases was determined according to previous diagnosis by a physician and medication use.

\section{Postmenopausal symptoms}

The most prevalent of the postmenopausal symptoms assessed were joint pain $(90.3 \%)$, followed by sleep problems (83.3\%), physical and mental exhaustion (80.0\%), hot flushes (76.8\%), depressive mood (74.5\%), heart discomfort $(72.8 \%)$, bladder problems (69.3\%), irritability (66.0\%), anxiety (58.0\%), vaginal dryness $(21.3 \%)$ and sexual problems (4.0\%) (Table 2).

Only 11 women (2.8\%) did not complain of any of these symptoms. Table 3 shows the distribution of the symptoms by degree of severity. All of the symptoms were present mainly to a mild or moderate degree rather than a severe or very severe degree, except for joint pain, which more women suffered to a severe/very severe degree than mild degree, and for bladder problems, which more women suffered to a severe degree than a mild degree.

The prevalence of symptoms was also assessed according to age group (Table 2). The oldest age group (> 85 years) had the highest prevalence of all symptoms except for heart discomfort, irritability, vaginal dryness and sexual problems. Using ANOVA, a statistically significant association was found between age and each of the following MRS symptoms: heart discomfort $(F=$ 1.623, $P=0.05)$, anxiety $(F=2.184, P=$ $0.003)$, bladder problems $(F=1.777, P$ $=0.02)$, and vaginal dryness $(F=2.068$, $P=0.006)$, but not with the other symptoms (Table 2).

On correlating the mean age and the score of each symptom (degree of severity), significant positive correlations were found between age and sleep problems, physical and mental exhaustion, bladder problems, depressed mood and anxiety, i.e. as age increase the severity of each of these symptoms increased (Table 4)

\section{MRS scores}

The total MRS score was 13.7 (SD 6.0) (range 0-31). Mean scores on the subscales were: 6.8 (SD 2.7) (range 0-15) for the somato-vegetative domain, 5.1 (SD 3.2) (range 0-16) for the psychological domain and 1.9 (SD 1.6) (range 0-8) for the urogenital domain. According to the degree of severity of the total MRS score, $50.3 \%$ of the assessed women had a moderate degree, $31.3 \%$ severe/very severe degree, whereas $11.5 \%$ a mild degree (Figure 1).

The mean total MRS score was higher among diabetics [14.4 (SD 5.6)] than non-diabetics $[13.2(\mathrm{SD} 6.3)](t=$ $2.09, P=0.037)$ and higher among hypertensives $[14.6(\mathrm{SD} 6.0)]$ than nonhypertensives $[11.7(\mathrm{SD} 5.6)](t=4.61$, $P<0.001)$. The mean illness summary score of the study group of women was 1.6 (SD 1.1), range 0-6.

The total MRS score increased with increasing age. This correlation was statistically significant $(r=0.153$, $P=0.002)$ and was independent using linear regression $(t=3.417, P=0.001)$. Significant positive correlations were also found with menopause duration $(r=0.166, P=0.001)$ and the chronic illness summary score $(r=0.357, P<$ $0.001)$, but not with menopause age, i.e. the MRS score increased with the increasing menopause duration and increasing number of chronic diseases suffered (Table 5).

\section{Discussion}

The menopause is receiving increasing attention in research studies due to the increasing life expectancy of women and the concomitant increase in postmenopausal life span. The mean age of menopause in the current study was 49.2 years, resembling many other previous studies, for example 50 years in the United States [10], 49.0 years in Singapore [11] and 48.6 years in Australia [12]. Postmenopausal symptoms have been shown to lead to social 


\begin{tabular}{|c|c|c|c|c|c|}
\hline \multirow{2}{*}{\begin{tabular}{|l} 
Variable \\
Age (years)
\end{tabular}} & \multirow[t]{2}{*}{ No. } & \multirow[t]{2}{*}{$\%$} & $\begin{array}{l}\text { MRS score } \\
\text { Mean (SD) }\end{array}$ & \multicolumn{2}{|c|}{ Significance } \\
\hline & & & & \multirow{4}{*}{$\digamma=5.473$} & \multirow{4}{*}{$P=0.005$} \\
\hline 65-75 & 349 & 87.2 & $13.4(5.9)$ & & \\
\hline $75-85$ & 43 & 10.8 & $16.3(6.4)$ & & \\
\hline$>85$ & 8 & 2 & $16.5(4.1)$ & & \\
\hline \multicolumn{6}{|c|}{ Marital status } \\
\hline Married & 138 & 34.5 & $13.7(5.7)$ & \multirow{3}{*}{$\digamma=1.270$} & \multirow{3}{*}{$P=0.282$} \\
\hline Widowed & 258 & 64.5 & $13.7(6.2)$ & & \\
\hline Divorced & 4 & 1 & $18.5(7.2)$ & & \\
\hline \multicolumn{6}{|c|}{ Age at menopause (years) } \\
\hline$<50$ & 198 & 49.5 & $13.9(5.9)$ & \multirow{2}{*}{$t=0.465$} & \multirow{2}{*}{$P=0.642$} \\
\hline$\geq 50$ & 202 & 50.5 & $13.6(6.1)$ & & \\
\hline \multicolumn{6}{|c|}{ Menopause duration (years) } \\
\hline$<18$ & 166 & 41.5 & $13.2(5.5)$ & \multirow{2}{*}{$t=1.645$} & \multirow{2}{*}{$P=0.101$} \\
\hline$\geq 18$ & 234 & 58.5 & $14.2(6.4)$ & & \\
\hline \multicolumn{6}{|c|}{ Hysterectomy } \\
\hline Yes & 15 & 3.8 & $13.0(3.5)$ & \multirow{2}{*}{$t=0.487$} & \multirow{2}{*}{$P=0.626$} \\
\hline No & 385 & 96.2 & $13.8(6.1)$ & & \\
\hline \multicolumn{6}{|l|}{ Hypertension } \\
\hline Yes & 281 & 70.2 & $14.6(6.0)$ & \multirow{2}{*}{$t=4.614$} & \multirow{2}{*}{$P=0.000$} \\
\hline No & 119 & 29.8 & $11.7(5.6)$ & & \\
\hline \multicolumn{6}{|l|}{ Diabetes } \\
\hline Yes & 181 & 45.2 & $14.4(5.6)$ & \multirow{2}{*}{$t=2.091$} & \multirow{2}{*}{$P=0.037$} \\
\hline No & 219 & 54.8 & $13.2(6.3)$ & & \\
\hline Coronary hec & & & & & \\
\hline Yes & 127 & 31.8 & $16.6(6.1)$ & & \\
\hline No & 273 & 68.2 & $12.4(5.5)$ & $t=6.865$ & $P=0.000$ \\
\hline Asthma & & & & & \\
\hline Yes & 20 & 5 & $18.9(6.6)$ & $t=3970$ & $P=0,000$ \\
\hline No & 380 & 95 & $13.5(5.9)$ & $l=3.9 / 0$ & $r=0.000$ \\
\hline Osteoporosis & & & & & \\
\hline Yes & 27 & 6.8 & $14.5(5.1)$ & & \\
\hline No & 373 & 93.2 & $13.7(6.1)$ & $t=0.661$ & $P=0.509$ \\
\hline Stroke & & & & & \\
\hline Yes & 3 & 0.8 & $23.3(4.5$ & $t=2798$ & $P=0005$ \\
\hline No & 397 & 99.2 & $13.7(6.0)$ & $l=2.190$ & $r=0.000$ \\
\hline Cancer & & & & & \\
\hline Yes & 4 & 1 & $17.8(6.7)$ & & \\
\hline No & 396 & 99 & $13.7(6.0)$ & $t=1.342$ & $P=0.181$ \\
\hline Thyroid disec & & & & & \\
\hline Yes & 3 & 0.8 & $16.3(13.7)$ & $t=0749$ & $P=0454$ \\
\hline No & 397 & 99.2 & $13.7(6.0)$ & $I=0.149$ & $P=0.454$ \\
\hline
\end{tabular}

impairment and work-related difficulties that significantly decrease women's overall quality of life [13]. Older women are also more vulnerable to social, economic and health disadvantages than older men [14].

The assessment tool used in the study - the MRS scale- has been widely used for investigating menopausal symptoms in many epidemiological and clinical researches [8]. The questionnaire was translated into Arabic 


\begin{tabular}{|c|c|c|c|c|c|c|c|c|c|c|}
\hline \multirow[t]{3}{*}{ Symptoms } & \multicolumn{6}{|c|}{ Age group (years) } & \multirow{2}{*}{\multicolumn{2}{|c|}{$\begin{array}{c}\text { Total } \\
(n=400)\end{array}$}} & \multirow{2}{*}{\multicolumn{2}{|c|}{$\begin{array}{c}\text { Significance of correlation } \\
\text { between age groups }\end{array}$}} \\
\hline & \multicolumn{2}{|c|}{$\begin{array}{c}65-75 \\
(n=349)\end{array}$} & \multicolumn{2}{|c|}{$\begin{array}{l}75-85 \\
(n=43)\end{array}$} & \multicolumn{2}{|c|}{$\begin{array}{c}>85 \\
(n=8)\end{array}$} & & & & \\
\hline & No. & $\%$ & No. & $\%$ & No. & $\%$ & No. & $\%$ & $F$-value & $P$-value \\
\hline Joint pain & 312 & 89.4 & 41 & 95.3 & 8 & 100.0 & 361 & 90.3 & 1.534 & 0.07 \\
\hline Sleep problems & 291 & 83.4 & 35 & 81.4 & 7 & 87.5 & 333 & 83.3 & 1.589 & 0.06 \\
\hline $\begin{array}{l}\text { Physical and mental } \\
\text { exhaustion }\end{array}$ & 277 & 79.4 & 36 & 83.7 & 7 & 87.5 & 320 & 80.0 & 1.266 & 0.20 \\
\hline Hot flushes & 270 & 77.4 & 30 & 69.8 & 7 & 87.5 & 307 & 76.8 & 0.758 & 0.76 \\
\hline Depressed mood & 257 & 73.6 & 34 & 79.1 & 7 & 87.5 & 298 & 74.5 & 1.494 & 0.08 \\
\hline Heart discomfort & 253 & 72.5 & 33 & 76.7 & 5 & 62.5 & 291 & 72.8 & 1.623 & 0.05 \\
\hline Bladder problems & 234 & 67.0 & 36 & 83.7 & 7 & 87.5 & 277 & 69.3 & 1.777 & 0.02 \\
\hline Irritability & 232 & 66.5 & 28 & 65.1 & 4 & 50.0 & 264 & 66.0 & 0.903 & 0.58 \\
\hline Anxiety & 195 & 55.9 & 30 & 69.8 & 7 & 87.5 & 232 & 58.0 & 2.184 & 0.003 \\
\hline Vaginal dryness & 66 & 18.9 & 18 & 41.9 & 1 & 12.5 & 85 & 21.3 & 2.068 & 0.006 \\
\hline Sexual problems & 15 & 4.3 & 1 & 2.3 & - & - & 16 & 4.0 & 0.375 & 0.99 \\
\hline
\end{tabular}

language and subjected to a linguistic validation for this study. The final Arabic version showed a good testretest agreement (90\%). Although it is a self-administrated questionnaire, face-to-face interviews were used in this study instead of self-completion by the respondents to minimize reporting errors due by the fact that a considerable number of the respondents had a limited level of education.

A search of the literature shows that other studies of menopausal symptoms have assessed women within a few years after menopause. Our aim was to assess postmenopausal symptoms in geripausal women so an older age range was selected (> 65 years) for the current study. Differences in the age range can explain the difference in symptom prevalence between our study and other studies of menopause. Differences between studies can also be attributed to differences in demographic characteristics and cultural attitudes to ageing and sexuality.

The prevalence of the classic symptom of menopause - hot flushes - was $76.8 \%$ in the current study. In another Egyptian study assessing a younger age group (women aged 50-59 years), the prevalence was $90.7 \%$ [15]. In most women, hot flushes resolve within a few years of menopause, but some women report symptoms for many years after they cease to menstruate [16]. The prevalence of hot flushes in older postmenopausal women has not yet been well documented, and it is not clear why hot flushes resolve in some women but continue for many years in others.

Several studies have been conducted to investigate postmenopausal symptoms among women in different countries and these suggest that menopausal status and symptoms vary

\begin{tabular}{|c|c|c|c|c|c|c|c|c|c|c|}
\hline \multirow[t]{2}{*}{ Symptom } & \multicolumn{2}{|c|}{ None } & \multicolumn{2}{|c|}{ Mild } & \multicolumn{2}{|c|}{ Moderate } & \multicolumn{2}{|c|}{ Severe } & \multicolumn{2}{|c|}{ Very severe } \\
\hline & No. & $\%$ & No. & $\%$ & No. & $\%$ & No. & $\%$ & No. & $\%$ \\
\hline Joint pain & 39 & 9.8 & 20 & 5.0 & 170 & 42.5 & 101 & 25.3 & 70 & 17.5 \\
\hline Sleep problems & 67 & 16.8 & 93 & 23.3 & 167 & 41.8 & 52 & 13.0 & 21 & 5.3 \\
\hline Physical and mental exhaustion & 80 & 20.0 & 81 & 20.3 & 163 & 40.8 & 61 & 15.3 & 15 & 3.8 \\
\hline Hot flushes & 93 & 23.3 & 101 & 25.3 & 154 & 38.5 & 44 & 11.0 & 8 & 2.0 \\
\hline Depressed mood & 102 & 25.5 & 145 & 36.3 & 111 & 27.8 & 30 & 7.5 & 12 & 3.0 \\
\hline Heart discomfort & 109 & 27.3 & 107 & 26.8 & 142 & 35.5 & 31 & 7.8 & 11 & 2.8 \\
\hline Bladder problems & 123 & 30.8 & 51 & 12.8 & 161 & 40.3 & 54 & 13.5 & 11 & 2.8 \\
\hline Irritability & 136 & 34.0 & 130 & 32.5 & 86 & 21.5 & 36 & 9.0 & 12 & 3.0 \\
\hline Anxiety & 168 & 42.0 & 93 & 23.3 & 106 & 26.5 & 25 & 6.3 & 8 & 2.0 \\
\hline Vaginal dryness & 315 & 78.8 & 39 & 9.8 & 28 & 7.0 & 16 & 4.0 & 2 & 0.5 \\
\hline Sexual problems & 384 & 96.0 & 6 & 1.5 & 7 & 1.8 & 1 & 0.3 & 2 & 0.5 \\
\hline
\end{tabular}




\begin{tabular}{lcc}
\hline \multicolumn{2}{l}{ Table 4 Correlation between age and menopause rating scale score in the study } \\
women $(\boldsymbol{n}=\mathbf{4 0 0})$ & \multicolumn{2}{c}{ Correlation with age } \\
\hline Symptom & $\boldsymbol{r}$ & $\boldsymbol{P}$-value \\
& 0.090 & 0.071 \\
Joint pain & 0.113 & 0.024 \\
Sleep problems & 0.144 & 0.004 \\
Physical and mental exhaustion & -0.027 & 0.596 \\
Hot flushes & 0.143 & 0.004 \\
Depressed mood & 0.062 & 0.218 \\
Heart discomfort & 0.141 & 0.005 \\
Bladder problems & -0.020 & 0.692 \\
Irritability & 0.145 & 0.004 \\
Anxiety & 0.094 & 0.059 \\
Vaginal dryness & -0.021 & 0.672 \\
Sexual problems &
\end{tabular}

across racial/ethnic groups $[17,18]$. In Poland hot flushes were the most commonly reported symptom by $96.4 \%$ [5], whereas among Arab and Greek women living in Australia it was 63\% and $43 \%$ respectively $[12,19]$ and it was as low as 3.9\% among Singaporean women [11]. In the United States, the prevalence of hot flushes was highest among African Americans (46\%),

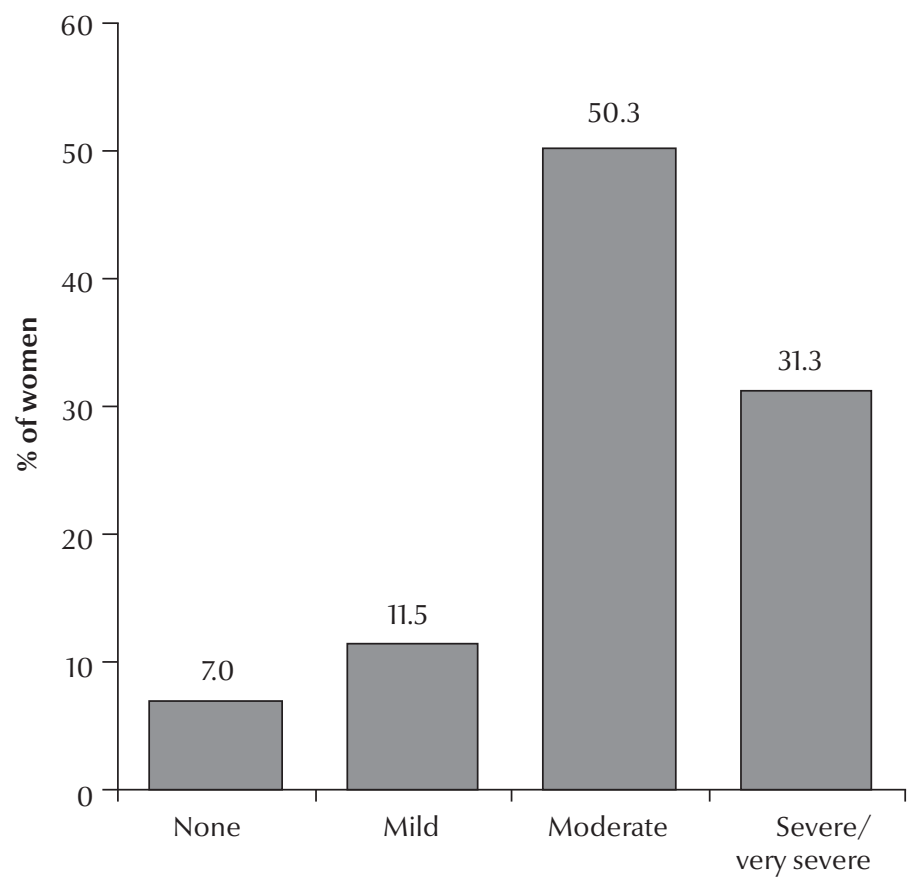

Figure 1 Distribution of women by severity of menopause rating scale (MRS) total score $($ none $/$ little $=0-4$, mild $=5-8$, moderate $=9-16$, severe $=17+[6])$ somatic or psychological symptoms experienced by women are not exclusively the result of changes due to menopause alone, but could also result from other physical, psychological or problems related to ageing in this group of women. These 3 symptoms were also the most prevalent in a Malaysian study, albeit with a lower rate $(80.1 \%, 67.1 \%$, $52.2 \%$ for joint pain, physical and sleep problems respectively) and based on a smaller age range [20]. The prevalence of joint pain increases progressively with age in women [12]. Menopausal and postmenopausal women sleep less than premenopausal women [21]. Twice as many postmenopausal women as premenopausal women report sleep disturbances [22]. Approximately 10 to $15 \%$ of these women consider themselves to have frequent significant to severe insomnia [23].

Hafiz et al. found higher scores for physical symptoms than for other symptoms among Indian women in Australia aged 45-65 years old [24]. Among Arab women living in Australia the most frequent symptom reported was found to be "feeling tired or worn out" (86\%), followed by "aching in muscles and joints"(85\%) [19]. The prevalence of fatigue among Greek women living in Australia was found to be $66 \%$ [12], while among Singaporean women of different racial groups the prevalence of muscle and joint aches was 52.6\% [11].

The prevalence of other psychological symptoms including depressed mood, irritability and anxiety ranged from $74.5 \%, 66.0 \%$ to $58.0 \%$ respectively in the current study. Tangen and Mykletun reported a significantly higher score of depression and anxiety in the postmenopausal period compared with the premenopausal period in Norway [25]. The most prevalent symptoms among aged women living in homes for old people in Brazil were depression and nervousness [26]. Among Greek women living in Australia 50\% complained of 


\begin{tabular}{lcc}
\hline \multicolumn{3}{l}{ Table 5 Correlation between menopause rating scale (MRS) total score and } \\
different variables \\
\hline Variable & \multicolumn{3}{c}{ Correlation with MRS } \\
& $\boldsymbol{r}$ & $\boldsymbol{P}$-value \\
Age & 0.153 & 0.002 \\
Menopause age & -0.023 & 0.652 \\
Menopause duration & 0.166 & 0.001 \\
Chronic llness summary score & 0.357 & $<0.001$ \\
\hline
\end{tabular}

psychosocial symptoms such as feeling nervous [12].

The prevalence of bladder problems was $69.2 \%$, but the prevalence of other symptoms in the urogenital subscale was much lower at $21.3 \%$ for vaginal dryness and only $4.0 \%$ for sexual problems. The low prevalence of sexual problems can be explained by low reporting due to reluctance to admit such problems in the conservative cultural context of Egypt or to diminished sexual desire among this age group. These rates resemble those of a study in Turkey showing prevalences of $68.8 \%$ for urinary incontinence and $23 \%$ for vaginal dryness among postmenopausal women above the age of 50 years [27].

Attempts were made to ensure that the study population was as representative as possible of the general population, yet there were some limitations to this study. This was a cross-sectional study, so it did not exclude other confounding effects that may influence experience of symptoms. In collecting data, women were asked to provide some retrospective information, hence recall bias is unavoidable. No participants of younger age were included to compare with this older age group, so further studies will be needed with a wider age range to compare age differences in symptom prevalence.

\section{Conclusions and recommendations}

An Arabic version of the MRS was prepared and subjected to linguistic validation. This tool can now be used for assessment of postmenopausal symptoms in Arabic-speaking countries. The most prevalent postmenopausal symptoms among geripausal Egyptian females were joint pain and sleep problems. Elderly females should be assessed for postmenopausal symptoms and physicians must be aware of this critical stage of life in women.

\section{References}

1. Hobbs FB, Damon BL. 65+ in the United States. Washington DC, United States Bureau of the Census, 2004.

2. Smith D, Tillipman H. The older population in the United States: population characteristics. Washington DC, United States Bureau of the Census, 2000.

3. Eskin BA, Troen BR. Geripause: a newly defined phase. Menopause Management, 2004, 13:12-17.

4. Endocrinology of postmenopause and geripause. In: Eskin BA. Troen BR, eds. The geripause. Medical management during the late menopause. New York, Parthenon, 2002:17-30.

5. Heinemann K et al. Reliabilitat der Menopause-Rating-Skala (MRS). Untersuchung fur die deutsche Bevolkerung. [Reliability of menopause-rating-scale (MRS). Investigation in the German population.] Zentralblatt fur Gynakologie, 2002, 124:161-163.

6. Heinemann $\mathrm{K}$ et al. Menopause rating scale (MRS): a methodological review. Health and Quality of Life Outcomes, 2004, 2:45.

7. Oskay UY, Beji NK, Yalcin O. Bladder symptoms in postmenopausal women. Acta Obstetricia et Gynecologica Scandinavica, 2005, 84:72-78.

8. Heinemann LAJ, Potthoff P, Schneider HPG. International vert sions of the Menopause Rating Scale (MRS). Health and Quality of Life Outcomes, 2003, 1:28.

9. Acquadro $\mathrm{C}$ et al. Languages and translation issues in quality of life and pharmaco-econonomics. Clinical Trials, 1996, 2:575-585.

10. Cramer DW et al. Cross-sectional and case-controlled analyses of the association between smoking and early menopause. Maturitas, 1995, 22:79-87.
11. Loh FH, Khin LW, Saw SM, Lee JJ, Gu K. The age of menopause and the menopause transition in a multiracial population: a nation-wide Singapore study. Maturitas, 2005, 52(3-4):169180.

12. Liu J, Eden J. The menopausal experience of Greek women living in Sydney. Menopause, 2008, 15(3):476-481.

13. Utian WH et al. The Utian Quality of life (UQOL) Scale: development and validation of an instrument to quantify quality of life through and beyond menopause. Menopause, 2002, 145:161-164.

14. Knodel J, Ofstedal MB. Gender and aging in the developing world: Where are the men? Population and Development Review, 2003, 29:677-698.

15. Loutfy I et al. Women's perception and experience of menopause: a community-based study in Alexandria, Egypt. Eastern Mediterranean Health Journal, 2006, 12:93-106.

16. Rossouw JE et al. Postmenopausal hormone therapy and risk of cardiovascular disease by age and years since menopause. Journal of the American Medical Association, 2007, 297:1465-1477.

17. Avis NE et al. Is there a menopausal syndrome? Menopausal status and symptoms across racial/ethnic groups. Social Science and Medicine, 2001, 52:345-356.

18. Gold EB et al. Relation of demographic and lifestyle factors to symptoms in a multi-racial/ethnic population of women 40-55 years of age. American Journal of Epidemiology, 2000, 152:463-473.

19. Lu J, Liu J, Eden J. The experience of menopausal symptoms by Arabic women in Sydney. Climacteric, 2007, 10(1):72-79.

20. Abdul Rahman SA, Zainudin SR, Kar Mun VL. Assessment of menopausal symptoms using modified Menopause Rating 
Scale (MRS) among middle age women in Kuching, Sarawak, Malaysia. Asia Pacific Family Medicine, 2010, 9:5.

21. Sloan JA et al. Methodologic lessons learned from hot flash studies. Journal of Clinical Oncology, 2001, 19:4280-4290.

22. ShaverJL, Zenk SN. Sleep disturbance in menopause. Journal of Women's Health and Gender-Based Medicine, 2000, 9:109-118.

23. Leger D, Guilleminault C, Dreyfus JP, et al. Prevalence of ini somnia in a survey of 12,778 adults in France. Journal of Sleep Research, 2000, 9:35-42.

24. Hafiz I, Liu J, Eden J. A quantitative analysis of the menopause experience of Indian women living in Sydney. Australian and New Zealand Journal of Obstetrics and Gynaecology, 2007, 47:329-334.
25. Tangen T, Mykletun A. the prevalence of anxious and depressive symptoms related to menstrual status. Journal of Psychosomatic Obstetrics and Gynaecology, 2008, 29:125-131.

26. Freitas LV et al. Prevalence of post-menopausal symptoms in aged women who are staying at homes for old people: a descriptive study. Brazilin Journal of Nursing, 2009, 8:1.

27. Stein MB, Barrett-Connor E. Quality of life in older adults receiving medications for anxiety, depression, or insomnia. Findings from a community-based study. American Journal of Geriatric Psychiatry, 2002, 10:568-574.

A strategy for active, healthy ageing and old age care in the Eastern Mediterranean Region 2006-2015

Population ageing or rapid increase in the number of older people is a global phenomenon. Nations are greying as the elderly population is growing much faster than the overall population due to decreasing fertility and increasing life expectancy. In most of the industrialized world, population ageing has been a gradual process following steady socioeconomic growth over several decades and generations. In the developing countries, the process is being compressed into two or three decades over a single generation. In 2050, there will be two billion people over the age of 60 years, $80 \%$ of whom will be living in developing countries. A strategy for active, healthy ageing and old age care in the Eastern Mediterranean Region 2006-2015 outlines strategic directions for Member States and delineates the role of the Regional Office in supporting Member States in achieving the stated objectives. The strategy is expected to enable senior administrators, policy-makers and decision-makers to face the challenge of population ageing.

This publication is available online at: http://www.emro.who.int/dsaf/dsa542.pdf 